\title{
Eğitim Laboratuvarlarında Güneş Enerji Verimliliğinin Araştırılması: İskenderun Örneği
}

\author{
Murat BİKÇE ${ }^{* 1}$, Ali Rıza ÇELIK ${ }^{2}$, Mustafa ÇAKIR ${ }^{2}$ \\ ${ }^{1}$ İskenderun Teknik Üniversitesi, İnşaat Fakültesi, İnşaat Mühendisliği Bölümü, Hatay \\ ${ }^{2}$ İskenderun Teknik Üniversitesi, İskenderun MYO, Elektronik Haberleşme Bölümü, Hatay
}

Geliş tarihi: 09.02.2016 Kabul tarihi: 22.04.2015

\section{Özet}

Ülkemizin enerji ihtiyacı yıllık ortalama \%3-5 arasında artış sergilemektedir. Üretilen enerjinin en büyük kısmının doğal gazdan elde edilmesi dışa bağımlılığı devam ettirmektedir. Elektrik kesintilerinden etkilenen sektörlerden biri de Eğitim alanıdır. Yenilenebilir enerji yöntemlerinden biri olan güneş enerjisi bakımından ülkemiz şanslıdır. Çevreci ve ucuz işletme maliyeti bakımından güneş enerjisinin eğitim alanına entegrasyonu önemli bir seçenektir. Bu çalışmada, günlük ihtiyacı yaklaşık $5 \mathrm{kWh}$ olan akıllı sistem modülleri ile donatılan İskenderun Meslek Yüksekokulu elektronik laboratuvarının enerji ihtiyacı, güneş enerji panel sistemleri tasarlanarak hazırlanmıştır. Sistem bir yıl boyunca izlenerek enerji verimliliği araştırılmış ve maliyet unsuru değerlendirilmiştir. Elde edilen verilere göre; kurulan sistemde kış aylarında enerji üretiminde düşüş olmasına rağmen yaklaşık yedi yılda kendisini amorti etmektedir. Eğitim-öğretimin devamlılığı ve güvenlik zafiyetinin önüne geçmek için bölge için kazançlı bir yatırım olacağı düşünülmektedir.

Anahtar Kelimeler: Akıllı binalar, PV, Yenilenebilir enerji, Güneş enerjisi, Yeşil enerji

\section{Investigation of Solar Energy Efficiency in Education Laboratory: Case Study İskenderun}

\begin{abstract}
The energy need of our country has been rising at an average between 3-5\% annually. Outside dependency continues since the largest part of the produced energy is obtained from natural gas. One of the sectors affected by the power outage is the education field. Our country is lucky in terms of solar energy which is one of the renewable energy methods. Integration of solar energy into the education field \footnotetext{
Mühendisliği Bölümü, Hatay.muratbikce@yahoo.com
}

* Yazışmaların yapılacağı yazar: Murat BİKÇE, İskenderun Teknik Üniversitesi, İnşaat Fakültesi, İnşaat
\end{abstract}


is an important option in terms of environmentalists and cheap operation costs. In this study, energy needs of Iskenderun Vocational School equipped with intelligent system modules having $5 \mathrm{kWh}$ daily needs are prepared by designing solar energy panel systems. Energy efficiency and cost factors are evaluated by monitoring the system for a year. According to the obtained data; even though there is a decline in energy production during the winter season with the established system, it pays for itself in approximately seven years. It is thought to be a profitable investment for the region in order to prevent security vulnerabilities and for the continuation of the education.

Keywords: Smart buildings, PV, Renewable energy, Solar energy, Green energy

\section{GİRIŞ}

Teknolojik gelişmelerin çok hızlı bir şekilde yaşandığı günümüzde günlük hayatı kolaylaştırmak için teknolojik alanda her geçen gün yeni gelişmeler olmaktadır. Konfor sağlamak adına otomasyon alanında tasarlanan sistemlerden olan "Akıllı Bina Sistemleri” insanların hayatlarını kolaylaştırırken enerjiye mutlak bağımlılığ arttırmaktadır [1, 2]. Bu enerjinin karşılanması fosil içerikli kaynaklar, nükleer enerji kaynakları ya da yenilenebilir enerji kaynaklarından sağlanabilmektedir. Fosil içerikli enerji üretim kaynaklarının (petrol, kömür, doğal gaz vb.) giderek tükenmeye yüz tutması ve bu kaynakların çevresel dengenin bozulmasındaki etkileri dikkate alındığında yenilenebilir enerjiye duyulan gereksinim gün geçtikçe artmaktadır. Yenilenebilir enerji kaynakları arasında güneş ve rüzgâr ön sıralarda yer almaktadır. Güneş ve rüzgâr enerjilerinin çevreye verdiği zarar günümüzde kullanilan enerji sistemleri ile karşılaştırılamayacak düzeyde azdır [3].

Güneş enerjisi, güneşin çekirdeğinde hidrojen'in helyum'a dönüşmesi ile meydana gelen füzyon sonrasında açığa çıkan enerjidir. Dünya atmosferinin dışında $\mathrm{m}^{2}$ başına düşen enerjinin şiddeti $1370 \mathrm{~W}$ iken bu değer atmosfer içerisinde $\mathrm{m}^{2}$ başına 0 ile $1100 \mathrm{~W}$ arasında değişmektedir [4]. $\mathrm{Bu}$ enerjinin büyüklüğü şu şekilde yorumlanabilir. Dünyaya inen güneş enerjisi miktarı, yeryüzünde şu ana kadar tespit edilmiş fosil yakıt miktarına göre ortalama 160 kat daha fazladır. Türkiye'de enerji üretimi; doğalgaz (\%31), barajl1hidroelektrik (\%24), kömür (\%21), akarsuhidroelektrik $(\% 10)$, termik $(\% 8)$, rüzgar $(\% 5)$, jeotermal (\%1), güneş (<\%1) kaynaklarından sağlanmaktadır [5]. Güneş enerjisi potansiyeli, hidroelektrik, fosil ve nükleer tesislerin yıllık üretiminden 15.000 kat daha fazladır [6]. Güneş enerjisi sistemlerinin başlıca üstünlükleri; işletme ve bakım maliyetlerinin düşüklügü, yıllarca sıkıntısız çalışması, modüler olması, temiz enerji olmasi.

Güneş enerjisi yenilenebilir olduğundan dolayı tükenmez ve diğer yakıtların aksine çevre ve insan sağlığı için önemli bir tehdit oluşturmazlar. Ayrıca, ülkemiz güneş potansiyeli açısından oldukça zengin bir ülkedir. Bu bakımdan güneş enerjisinin devamlılığı açısından şanslıdır. Bu şans kullanılarak enerji kaynağının kullanılabilir enerji türüne dönüștürülebilmesi önemlidir. Bu nedenle kendi enerjisini kendi üretecek sistemlerin tasarlanması ülke açısından önemlidir.

\section{MATERYAL VE METOT}

İskenderun bölgesinde sanayinin yoğun olması, var olan sanayinin demir-çelik üretimi ve işlenmesine yönelik olmasından dolayı büyük oranda enerjiye gereksinim duyulmaktadır. Bu yüksek enerji ihtiyacının karşılanması için çevresel dengeyi bozacak nitelikte gaz salınımı yapan termik santraller kurulmaktadir. $\mathrm{Bu}$ durumun aksine bölgemizde buna karşı rüzgâr ve güneş enerjisi potansiyelinin bölgemiz açısından yüksek olması münasebetiyle bu yöndeki çalışmaların yapılmasını gerekli kılmaktadır.

Yeni yapılan akıllı binalarda kullanımı yaygınlaşmaya başlayan; kamera, kartlı anahtar gibi güvenlik teknoloji ürünlerinin ve eğitim laboratuvarlarındaki elektronik aletler elektrik 
kesintileri ile sık sık karşılassmaktadır. Bu kesintiler nedeniyle, aletler bozulmakta, güvenlik zafiyeti oluşmakta, eğitimin kesintiye uğraması ile karşı karşıya kalınmaktadır. Yaşanan bu ciddi kaybın önüne geçmek amacıyla bu türdeki teknolojik ürünlerin kendine yetecek enerjisini güneş enerjisi ile sağlayarak mevcut kaynakların verimliliği ve ekonomikliği araştırılmıştır. İskenderun bölgesi, hem rüzgar hem de güneş enerjisi açısından oldukça verimlidir. $\mathrm{Bu}$ kaynakların eğitimde kullanılarak ekonomiye katkı sağlanabilirliğinin araştırılması amacıyla bu çalışma yürütülmüştür.

Elektrik İşleri ve Etüt İdaresinin tüm Türkiye [7] ve Hatay [8] için günlük $\mathrm{m}^{2}$ başına düşen global radyasyon değerleri ile gün içerisinde aylara göre toplam güneş alma süreleri saat cinsinden Şekil 1'de görülmektedir.

Güneş enerjisi ile elektrik üretiminde dikkate alınacak hususlar; günlük güneşlenme süresi (saat) ve bulutluluk oranıdır. Ülkemizin iller bazında toplam güneş radyasyonları göz önüne alındığında Hatay İlinin yıllık $\mathrm{m}^{2}$ başına 1600-1650 kWh güneş enerji potansiyeli olduğu Şekil 1'de görülmektedir. Ayrıca Elektrik İşleri ve Etüt İdaresinin verilerine göre Hatay ilinin günlük ortalama global radyasyon ve güneşlenme süreleri açısından Türkiye ortalamasının üzerinde olduğu Şekil $2 a-d$ incelendiğinde görülmektedir.

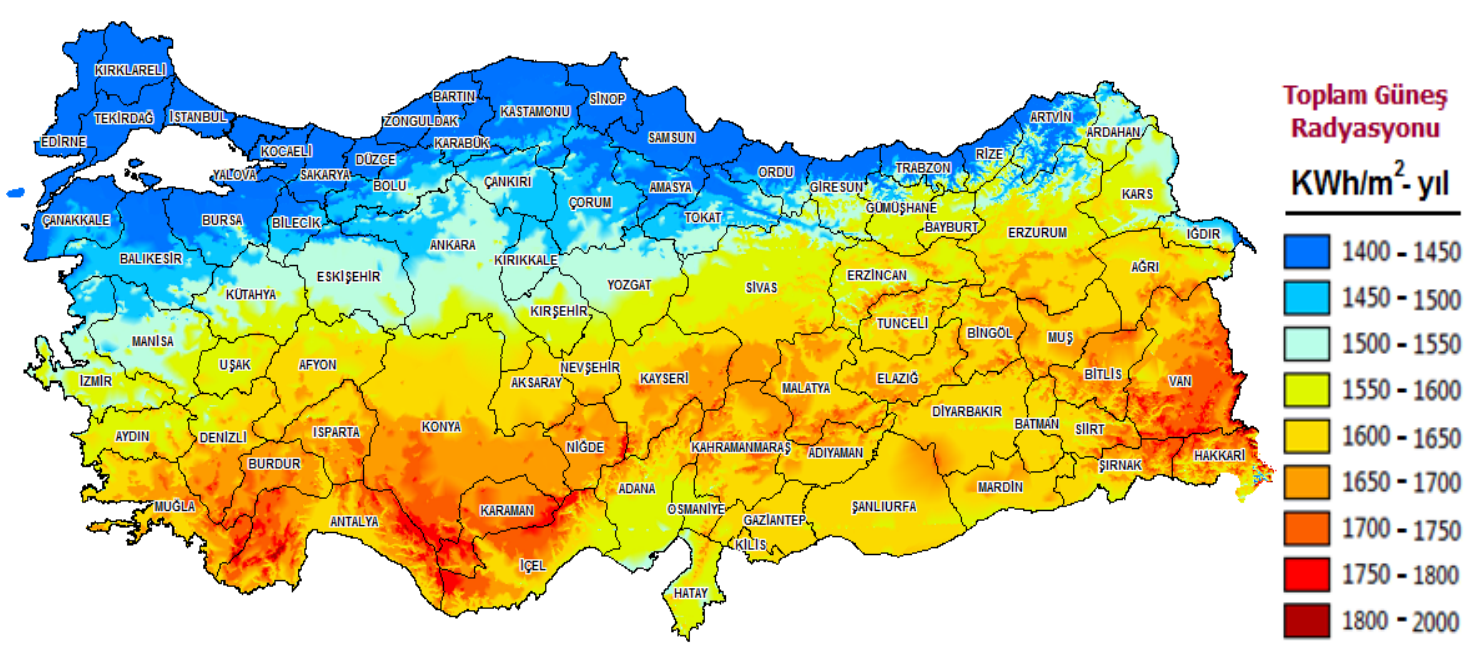

Şekil 1. Türkiye için yıllık ortalama güneş radyasyonu haritası

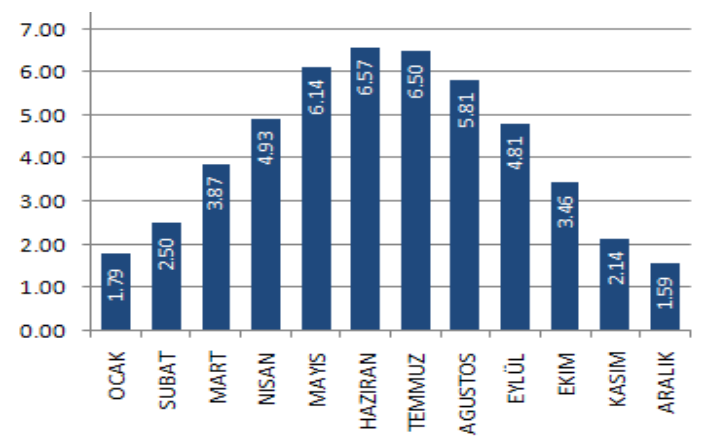

Şekil 2a. Türkiye global radyasyon değerleri $\left(\mathrm{kWh} / \mathrm{m}^{2}\right.$-gün)

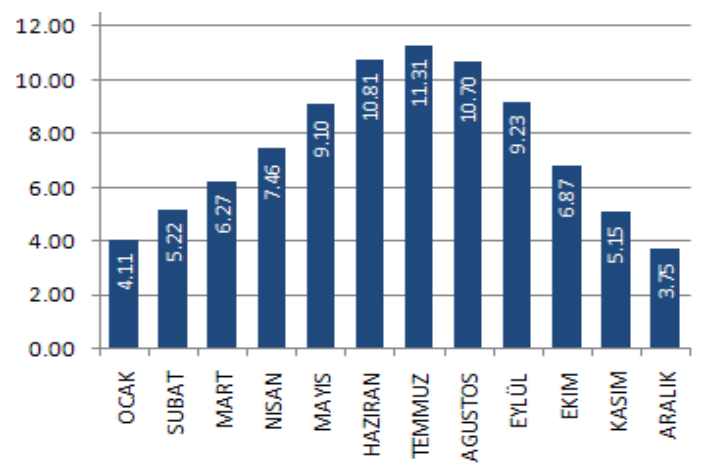

Şekil 2b. Türkiye güneşlenme süreleri (saat) 


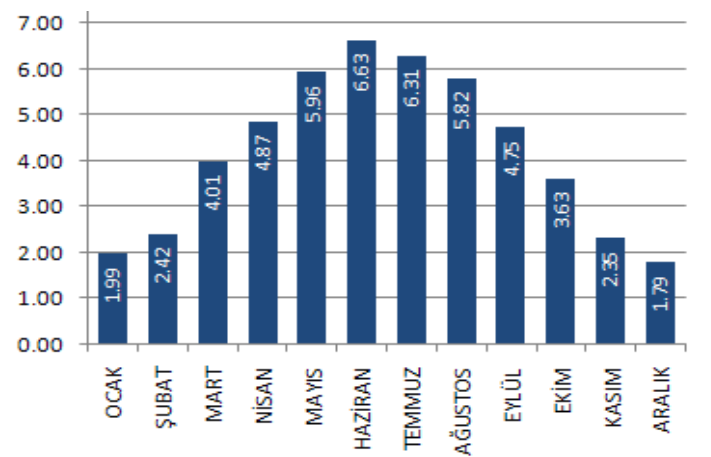

Şekil 2c. Hatay global radyasyon değerleri $\left(\mathrm{kWh} / \mathrm{m}^{2}\right.$-gün)

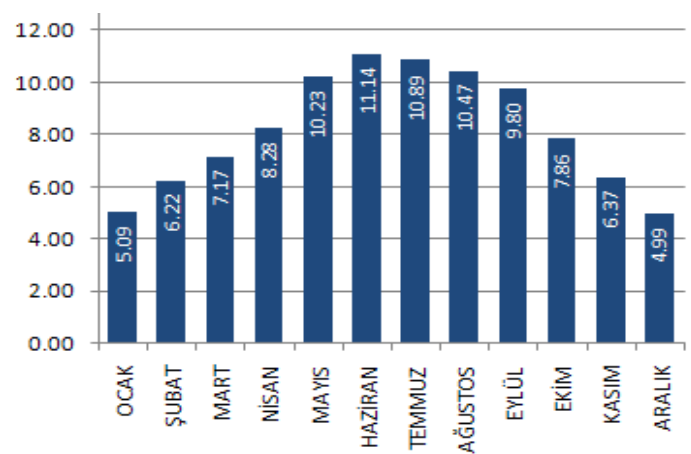

Şekil 2d. Hatay güneşlenme süreleri (saat)
PV sistemini olușturan temel bileșenler Şekil 3'de görüldüğü gibi güneş panelleri, akümülatörler ve invertörden ibarettir.

Güneş enerjisi ile elektrik üretme sistemimizde mevcut enerji 6 adet Foto-voltaik (PV) panel İskenderun Meslek Yüksekokulu (İMYO) çatısına kurulan çelik konstrüksiyon üstüne yerleştirilmiştir (Şekil 4).

PV panellerinin ürettiği DC gerilimi depolamak için 4 adet seri akü grubu oluşturulmuştur (Şekil 5). Özellikle yaz aylarında kuvvetli aydınlanma sonucu PV panellerinin üreteceği yüksek DC şarj söz konusudur.

Aşırı şarj geriliminin akülere zarar vermesini engellemek ve regülasyonu sağlamak üzere her akü grubuna birer adet akü şarj regülatörü sistemde kullanılmıştır (Şekil 6).

DC biçiminde akülerde depolanan gerilimin eğitim laboratuvarı içinde kullanılan tüm alet ve cihazları besleyebilmesi için bir adet $3 \mathrm{kVA}$ gücünde invertör kullanılmıştır (Şekil 7).

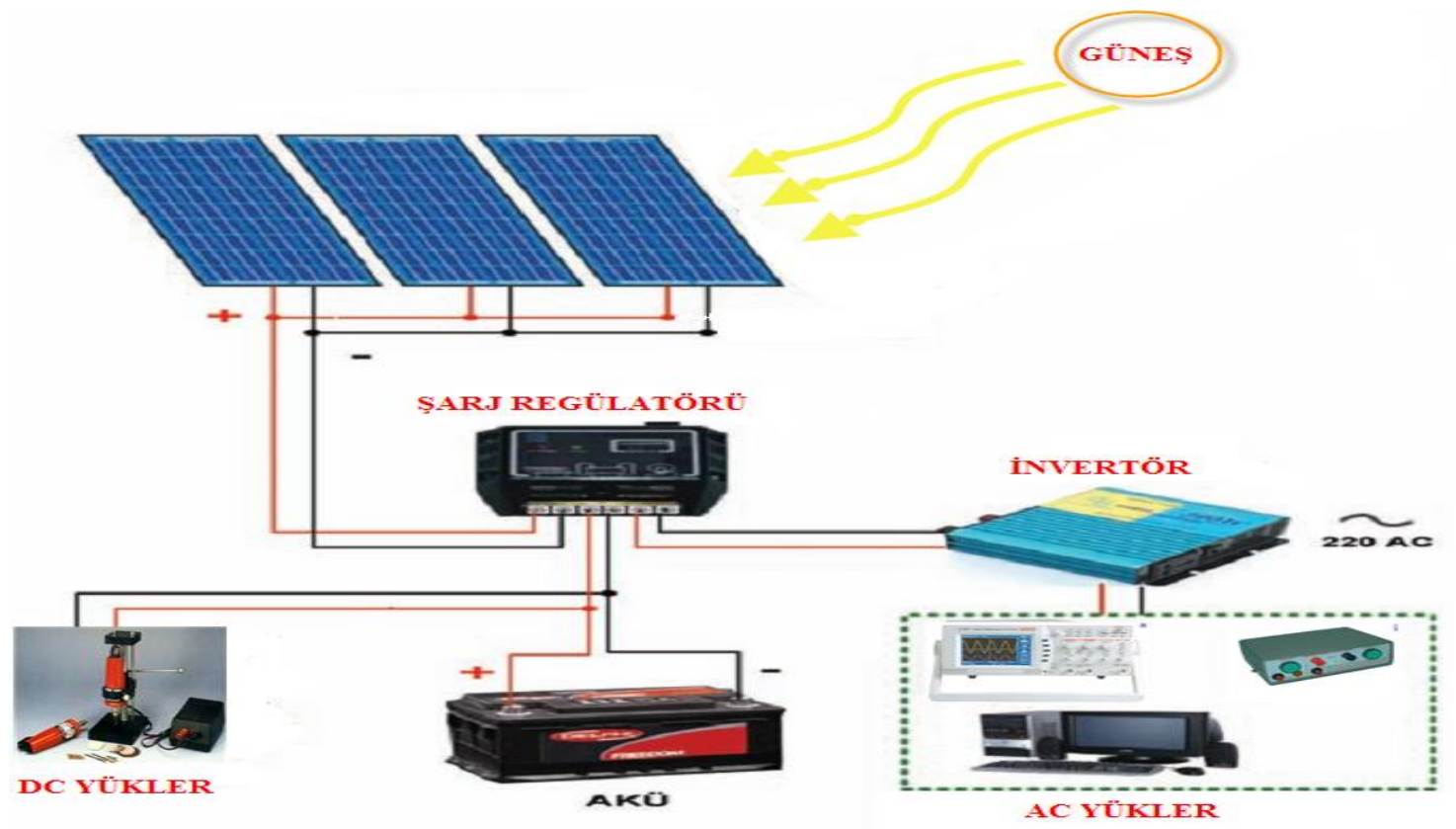

Şekil 3. PV sistemin bileşenleri 


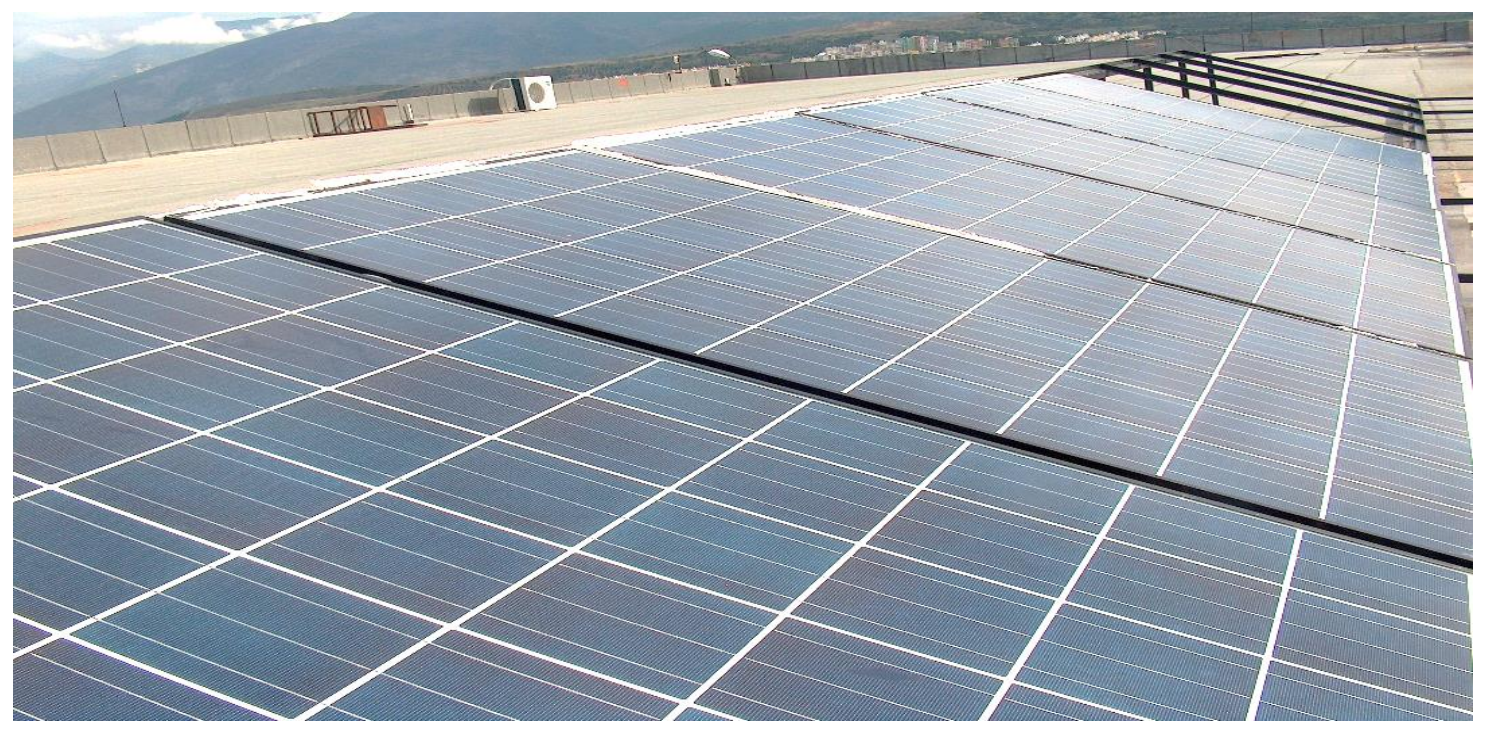

Şekil 4. PV sistemin bileşenleri

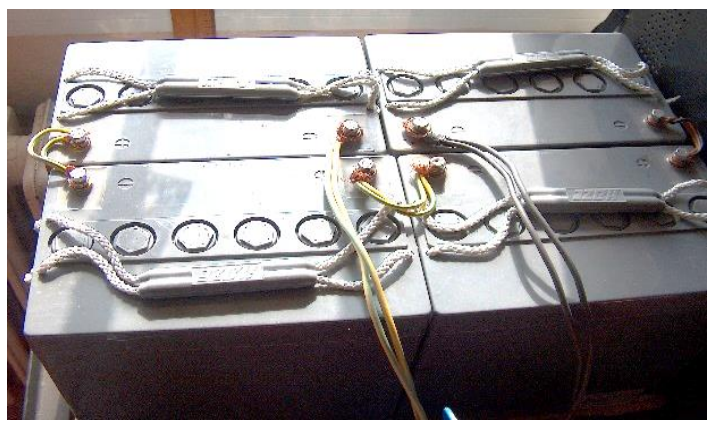

Şekil 5. Akü grubu

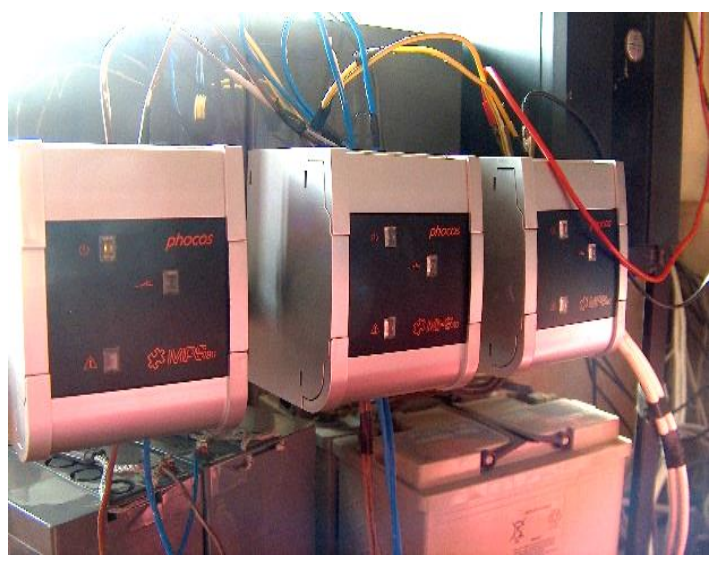

Şekil 6. Akü şarj regülatörleri

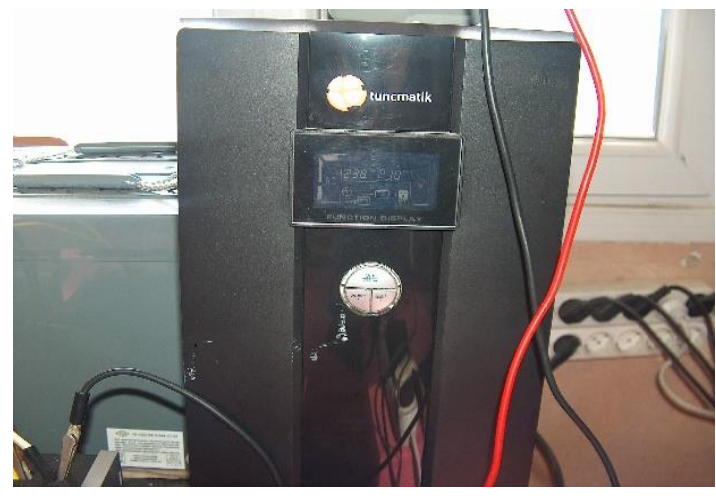

Şekil 7. 3kVA gücünde İnvertör

Kazanılan enerjinin verimliliğinin ölçmek için öncelikle İskenderun Meslek Yüksekokulunda kullanılan; kameralı güvenlik sistemi, şifreli, kartlı ve parmak izi okuyucu, akıllı sistemler, akıllı tahta, laboratuvar deney setleri, osiloskoplar, projeksiyon cihazları ve bilgisayar gibi teknolojik ürünler Elektronik Laboratuvarında toplanmıştır. Böylece, teknolojik aletlerin ani elektrik kesintilerinde zarar görüp görmeyeceği, eğitim-öğretimin kesintisiz devam edip etmeyeceği ve güvenlik zafiyetinin oluşup oluşmayacağı incelenmiştir.

$\mathrm{Bu}$ çalışmada kullanılan cihazlar ve bunların talep ettiği güç miktarları Çizelge 1'de sıralanmıştır. 
Çizelge 1. Elektronik laboratuvarındaki cihazların birim ve toplam güç harcaması

\begin{tabular}{|lcccc|}
\hline Cihaz Adı & Adet & $\begin{array}{c}\text { Birim Güç } \\
\text { Harcaması }\end{array}$ & $\begin{array}{c}\text { Ort. Günlük } \\
\text { Çalışma Süresi }\end{array}$ & $\begin{array}{c}\text { Toplam } \\
\text { Harcanan } \\
\text { Güç̧ }\end{array}$ \\
\hline Osiloskop & 4 & $50 \mathrm{~W}$ & 1,5 & $300 \mathrm{~W}$ \\
Deney Seti & 5 & $30 \mathrm{~W}$ & 1,5 & $225 \mathrm{~W}$ \\
Aydınlatma Elemanı & 6 & $26 \mathrm{~W}$ & 3 & $468 \mathrm{~W}$ \\
PC & 1 & $200 \mathrm{~W}$ & 8 & $1600 \mathrm{~W}$ \\
Projeksiyon Cihazı & 1 & $260 \mathrm{~W}$ & 8 & $2080 \mathrm{~W}$ \\
Akıllı Tahta & 1 & $5 \mathrm{~W}$ & 8 & $40 \mathrm{~W}$ \\
Güvenlik Kamerası & 3 & $3 \mathrm{~W}$ & 24 & $216 \mathrm{~W}$ \\
Parmak İzi Okuyucu & 1 & $4 \mathrm{~W}$ & 8 & $32 \mathrm{~W}$ \\
Kartlı Geçiş Sistemi & 1 & $4 \mathrm{~W}$ & 8 & $32 \mathrm{~W}$ \\
\hline Genel Toplam (anlık max. güç harcaması) & $=1006 \mathrm{~W}$ & & & $4993 \mathrm{~W}$ \\
\hline
\end{tabular}

Şekil 2d'de görüldüğü üzere Hatay ili şartlarında güneşlenme süresinin en az olduğu ay Aralık ayı olup yaklaşık olarak 5 saat olmaktadır. Günlük ortalama yük ihtiyac1 $5 \mathrm{kWh}$ olan bir laboratuvar için; ortalama güneşlenme süresinin 5 saat olduğu varsayılarak saatlik 1, $2 \mathrm{KW}$ 'lı üretim yapan bir güneş paneli sistemi tasarlanması laboratuvarın enerji ihtiyacını karşılamıştır. Paneller üzerlerine düşen 1şı̆̆ın şiddetine bağlı olarak güç üretebilmektedirler. Panel camının kirlenmesi, güneş 1şınlarının sabah ve akşam dik açıyla gelmemesi, havanın çok sıcak ve çok soğuk olup verimin düşmesi gibi nedenlerden ötürü $1,2 \mathrm{kWh}$ 'lık panel günlük $5 \mathrm{kWh}$ ihtiyacı rahatlıkla karşılamıştır. Bir gün güneş çıkmaması durumunda sistemin işler durumda olabilmesi açısından günlük tüketimi yaklaşık $5 \mathrm{KW}$ olan laboratuvar için bu gücü karşılayacak akü kapasitesi gerekli olmuştur. 6 adet seri ve 2 paralel koldan oluşan $72 \mathrm{~V}-110 \mathrm{Ah}$ 'lik akü grubu $72 \mathrm{~V}^{*} 110 \mathrm{Ah}=7920 \mathrm{~W}$ depolayabilir. Akülerde depolananın tamamını hatta \%70'inden fazlasını kullanmak akünün yapısını kısa zamanda bozmaktadir [9]. $7920 * 0,7=5544 \mathrm{~W}$ olmaktadır. Bu yüzden $72 \mathrm{~V}$ 110Ah'lik bir akü grubu tasarlanan sistem için ideal olmuştur. $12 \mathrm{~V}$ gerilim değeri ve $1,2 \mathrm{KW} \mathrm{PV}$ sistemi için Çizelge 1'e göre 48V 80A'lik bir akü şarj regülâtörü kullanılmıştır. PV panellerin ürettiği DC enerjiyi binalarda kullanılan $\mathrm{AC}$ enerjiye (220V-50 Hz) çevrilmesi işlemini invertör gerçekleștirmektedir. Aynı anda maksimum güç talebi laboratuvardaki tüm cihaz ve aletlerin çalışması sonucu anlık maksimum güç talebi $1006 \mathrm{~W}$ olmaktadir. Bu durumda $12 \mathrm{~V}$ DC-230V AC $50 \mathrm{~Hz}$ frekans dönüşümlü $3 \mathrm{KW}$ gücünde bir invertör kullanılmıştır.

\section{BULGULAR VE TARTIŞMA}

Kurulan PV sisteminde 12 ay boyunca günlük olarak panel üzerine düşen 1 şık şiddeti miktarı lüx cinsinden ve panel gruplarının ürettiği gerilim değerleri Volt cinsinden veri kaydetme (datalogger) cihazları yardımıyla dört dakikalık periyotlar ile kaydedilmiştir (Şekil 7).

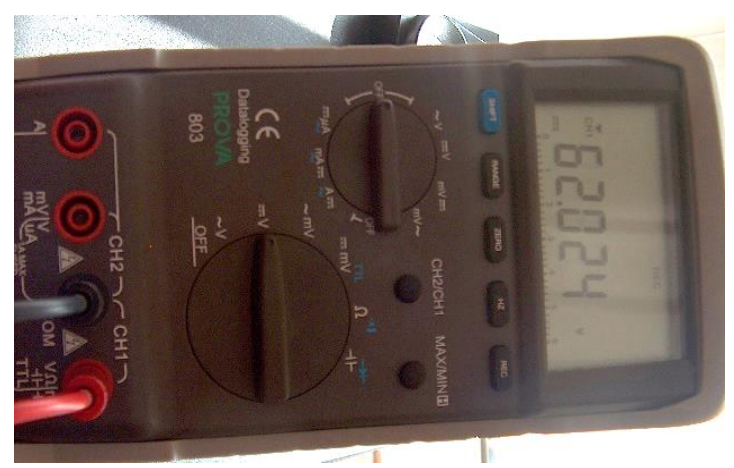

Şekil 7. Gerilim ve 1şık şiddeti değerlerinin kaydedilmesi 
Gerilim ve Işık şiddeti Datalogger cihazlarından csv (comma separated value) formatında toplanan günlük verilerin aylık ortalamaları hesaplanarak günlük güneşlenme sürelerinden yola çıkarak aylara göre dağılımları hesaplanmış ve Şekil 8'deki grafikte sunulmuştur. Grafikte görülen 1-3 verilerin açıklaması sırasıyla;
Veri 1: İSKENDERUN için aylık ortalama güneşlenme süresi [8]

Veri 2: BELEN için aylık ortalama güneşlenme süresi [8]

Veri 3: $\mathrm{Bu}$ çalışmada yapılan ölçümler neticesinde Laboratuvar'ın bulunduğu yer için aylık ortalama güneşlenme süresini göstermektedir.

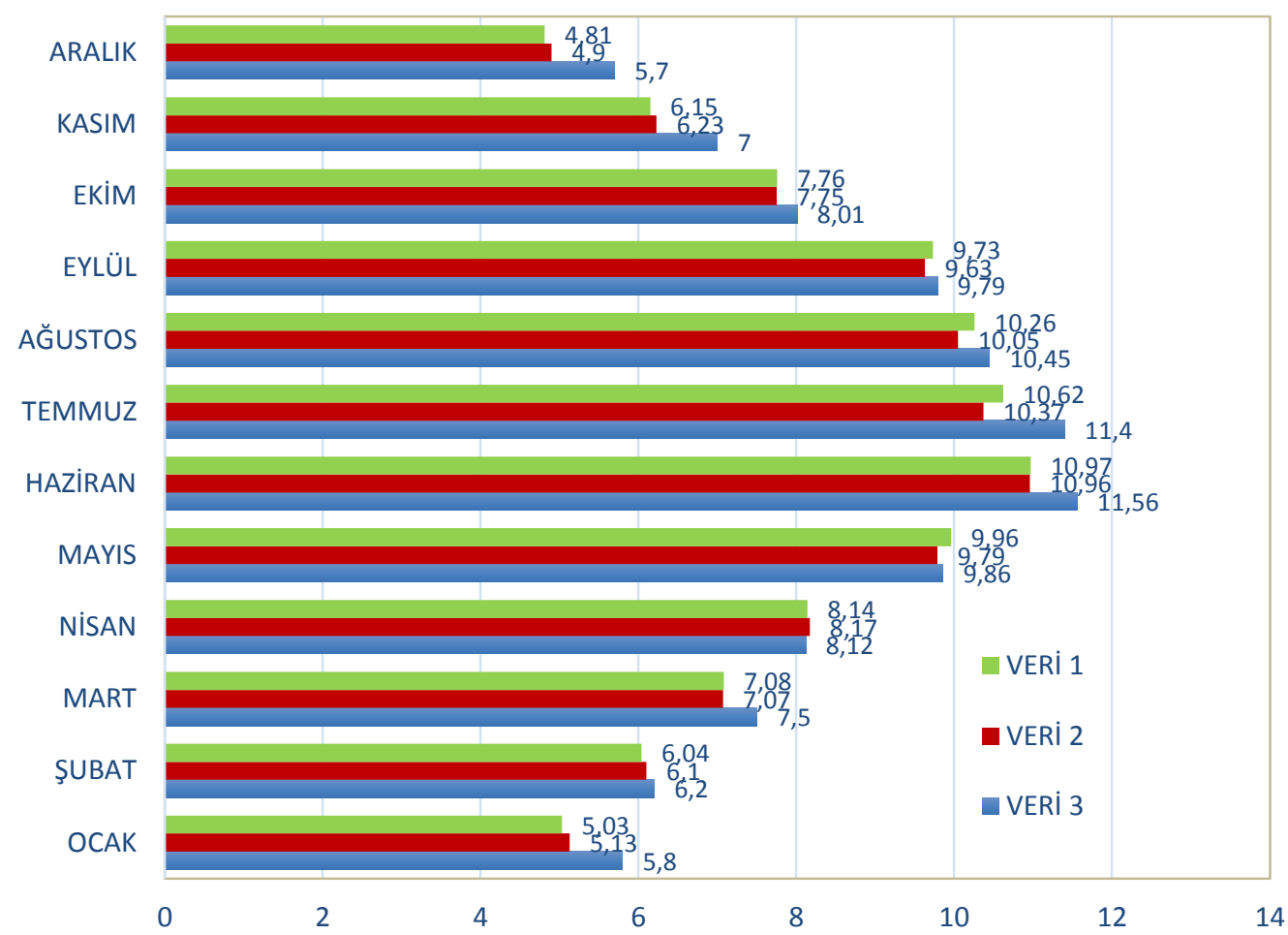

Şekil 8. Günlük güneşlenme sürelerinin saat cinsinden aylara göre dağglımı

Bu çalışmada oluşturulan PV sistemi tarafindan elde edilen aylık ortalama güç dağılım değerleri ve üretilen güç değerinin EPDK [10] verilerine göre Türk Lirası karşılıkları Şekil 9'da gösterilmiştir. Grafikte görülen 1-3 verilerin açıklaması sırasıyla;

Veri 1: Aylara göre ortalama tarife karşılı̆̆ $(\mathrm{kr} / \mathrm{kWh})$

Veri 2: $\quad$ PV sisteminin elde ettiği güç $(\mathrm{kW})$

Veri 3: $\quad$ PV sisteminin elde ettiği gücün karşılığ (TL)

\section{SONUÇLAR}

Ülkemizin birçok bölgesinde olduğu gibi İskenderun bölgesi de rüzgâr ve güneş enerjisi bakımından verimlidir. Mevcut bu kaynakları kullanarak eğitimde devamlılık ve ekonomiye katkı sağlanması amacıyla bu çalışma yürütülmüştür. Eğitim alanlarında ve akıllı binalarda kartlı anahtar, projeksiyon cihazı, kamera vb. güvenlik teknoloji ürünlerinin kullanımı gitgide yaygınlaşmaktadır. 


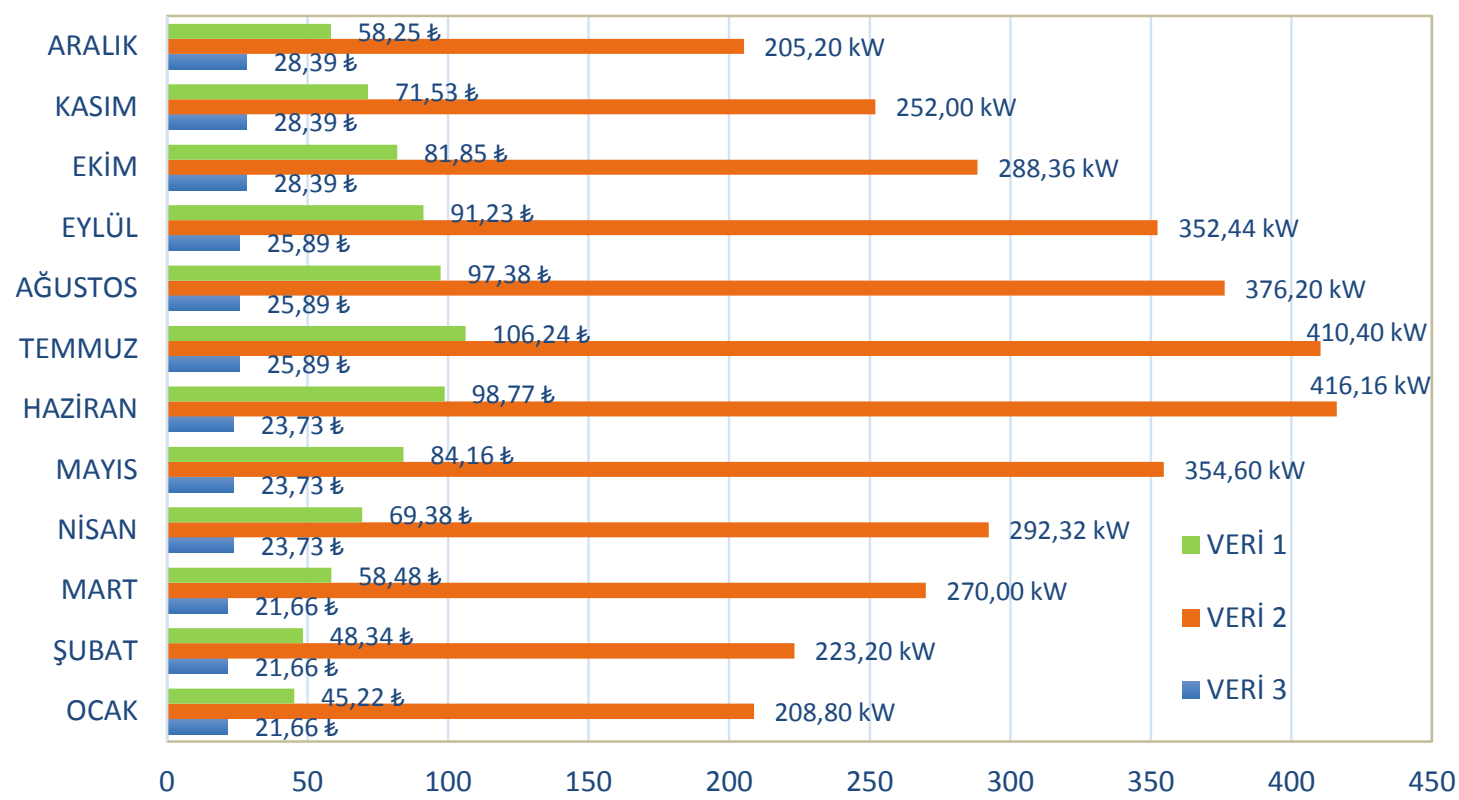

Şekil 9. Aylara bağlı ortalama elde edilen güç ve bu gücün parasal karşılığının grafiksel dökümü

$\mathrm{Bu}$ elektronik aletlerin elektrik kesintilerinden dolayı olumsuz etkilenerek bozulması, güvenlik zafiyetinin oluşması, eğitimin devam etmemesi ve boşa giden enerjinin önüne geçmek amacıyla bu türdeki teknolojik ürünlerde verimliliği incelenmiştir. Bu çalışmada oluşturulan PV sistemi sayesinde bir taraftan ölçümler yapılırken bir taraftan elde edilen enerjinin verimliliği çok sayıdaki laboratuvar cihazı ve teknolojik ürün üzerinde incelenmiştir. Meydana gelen ani elektrik kesintilerine bağlı olarak teknolojik aletlerin zarar görüp görmeyeceği, eğitim-öğretimin kesintisiz devam edip etmeyeceği ve güvenlik zafiyetinin oluşup oluşmayacağı incelenmiştir.

Kurulan PV sistemi ile bir yıl boyunca güneş enerjisinden elde edilen verim ölçülmüştür. En düşük enerji üretimi $205,20 \mathrm{~kW}$ ile aralıkta, en yüksek enerji üretimi 416,16 kW ile haziran ayında elde edilmiştir. Ortalama aylık enerji üretimi 304,14 kW elde edilmiştir. Ortalama yıllık elektrik üretimi yaklaşık olarak $3650 \mathrm{~kW}$ olmuştur. $\mathrm{Bu}$ kazanımın EPDK'nın belirlediği ortalama birim $\mathrm{kWh}$ ücretine göre parasal karşılığ1 yıllık 910,85 TL olmuştur. Kurulumu yaklaşık 7000 TL civarında mal olduğuna göre enerji sisteminin kendini amorti süresi yaklaşık 7 yıldır. Her akıllı bina veya laboratuvarlar için yeterli olacak sistem tasarlanmalıdır. Maliyeti arttıran en önemli husus; enerji depolama teknolojisindeki yüksek kurulum ve bakımdır. Ayrıca, rüzgâr enerjisinin de sisteme entegre edilmesi ile özellikle kış aylarında enerji üretiminde devamlılık kazanılacağı ve verimliliğin artacağı aşikardır. Özellikle eğitim-öğretimin devamlılığ 1 ve akıllı bina teknoloji ürünlerindeki güvenlik zafiyetinin önüne geçmek için benzer bölgelerde orta vadede kendisin amorti edecek kazançlı bir yatırım olacağı düşünülmektedir.

\section{TEŞEKKÜR}

Bu çalışma; Mustafa Kemal Üniversitesi Bilimsel Araştırma Projeleri (BAP) Koordinasyon Birimi tarafından desteklenmiştir (Proje No: BAP250).

\section{KAYNAKLAR}

1. Gençoğlu M.T., 2008. Akıllı Evler, I. Mühendislik ve Teknoloji Sempozyumu, 221-234, Ankara. 
2. Erol Y., 2008. Telefonla Uzaktan Cihaz Kontrolü, Bilim ve Teknik Dergisi, Nisan Sayıs1.

3. Özgöçmen A., 2007. Güneş Pilleri Kullanarak Elektrik Üretimi. Gazi Üniversitesi. Fen Bilimleri Enstitüsü.

4. http://tr.wikipedia.org/wiki/Güneş_enerjisi. Erişim tarihi: 10.02.2015

5. Elektrik mühendisleri odası www.emo.org.tr. Erişim tarihi: 10.02.2015

6 Varınca K.B., ve Gönüllü M.T., 2006. Türkiye'de Güneş Enerjisi Potansiyeli ve Bu Potansiyelin Kullanım Derecesi, Yöntemi ve Yaygınlığı Üzerine Bir Araştırma, UGHEK'2006: I. Ulusal Güneş ve Hidrojen Enerjisi Kongresi, ESOGÜ, Eskişehir.

7. Yenilenebilir Enerji Genel Müdürlüğü, http://www.eie.gov.tr/MyCalculator/Default.as px. Erişim tarihi: 10.02.2015

8. Yenilenebilir Enerji Genel Müdürlüğü http://www.eie.gov.tr/MyCalculator/pages/31.a spx. Erişim tarihi: 10.02.2015

9. Köroğlu T., Teke A., Bayındır K.Ç., Tümay M., 2010. Güneş Paneli Sistemlerinin Tasarımı, Elektrik Mühendisliği Dergisi, Sayı: 439, 98-104.

10. Enerji Pisasası düzenleme kurumu, http://www.epdk.gov.tr/index.php/elektrikpiyasasi/tarifeler?id=133. Erişim tarihi: 10.02.2015 
